\title{
Post war reconstruction period 1940-1970: steel and concrete structures in The Netherlands
}

\author{
G. G. Nieuwmeijer \\ Delft University of Technology, Faculty of Architecture, \\ Delft, The Netherlands
}

\begin{abstract}
This period is characterized by the development of existing building materials and steel and concrete structures, as well as by the use of new materials such as prestressed concrete and lightweight concrete.

Steel construction methods led to the appearance of new forms such as space frames, suspended roof structures, shell structures and orthotropic decks on bridges. For concrete structures it was primarily new construction systems deriving from the employment of prefabrication and sliding formwork and new methods of calculation, which led to advances.

Surveys and the typology of structures lead, on one the hand, to the assessment of historical cultural values, while on the other hand, information is acquired for transformations with the regard to changes in function. Examples of both typical and uncommon structures are given.

Keywords: reconstruction, steel, concrete prefabrication, prestressed, roofstructures.
\end{abstract}

\section{Introduction}

The growing interest in the Reconstruction Period and questions relating to the transformation of buildings were reasons why the History of Structural Design Group of the Faculty of Architecture started research on this subject.

The structures of the period $1850-1940$ also influence the architecture of this period and the cultural historical value of the buildings. Many building from this period have already been demolished, or are threatened with demolition. Why not reuse these buildings? The transformation of buildings, however, demands understanding of their structural design. 
The reconstruction period can be subdivided into two periods. The first, from 1940-1950, was characterised by the repair and rehabilitation of war damage. There was a shortage of money and of building materials and traditional materials such as brick and timber were mainly used. Even distorted steel bars were frequently reused after mechanical straightening. There was also a lack of handling equipment and machinery on the construction sites. This was a time economical use of material and greater efficiency started with, for instance, the introduction of new calculation methods, saving steel by welding instead of riveting and mixing concrete in a plant instead of on the construction site. In the second period, 1950-1960, the economy was slowly growing under the Law of Reconstruction and the Marshall plan. The Law of Reconstruction made quicker procedures and government subsidies possible. From the mid-fifties economic growth really took off and labour was in short supply. The previously mentioned trends continued, the quality of building materials improved and new techniques were used.

\section{Steel structures}

\subsection{Material}

In the fifties the Federal Republic of Germany became the most important accelerator of the West European economy. Trade between Germany and the Netherlands could profit from the expansion of the steel industry. The quality of steel was improved by better control of the production process and stronger types of steel became available. Engineers were better educated by manuals and publications of the Staalbouwkundig Genootschap (Steel Construction Society) which was founded in 1961.

Delft University of Technology also promoted research in the application of steel by Professor. Ir. A.A. van Douwen. The building regulations of 1949 made possible the use of higher admissible stresses, while the evolution of calculation methods made calculation easier and more accurate. The Cross method offered new possibilities for the construction of statically determined structures and scale rules gave way to electric calculators, followed by electronic calculators and then computers.

Welding and cutting techniques were improving and the education of welders and the controlling of joints by roentgen equipment led to more reliable welded steel structures. Thanks to improved electrodes, welding could be used not only be used in the workshop, but also on the construction site. The switch from riveted joints to welded connections provided a saving of material and labour. The evolution of prestressed bolts also led to better connections between elements. Heavier means of transport, like cranes and lorries were designed to transport materials and prefabricated elements from the workshop to the construction sites. It became possible to handle larger construction elements.

The safety coefficient, now loading factor, is now lower than in the Reconstruction period, which opens possibilities for the reuse of buildings. 


\subsection{Building methods}

Until 1950 steel was scarce and foreign currency was required for its import. Reinforcement steel and cement were made by the Hoogovens blast furnace company at Ijmuiden. After 1950 it became easier to obtain steel, although the delivery times for steel profiles remained unreliable. The choice between steel and concrete usually fell on concrete, partly because the main contractor of a large building was often a 'concrete' builder. Steel was more often used for large hall than for multi-storey buildings.

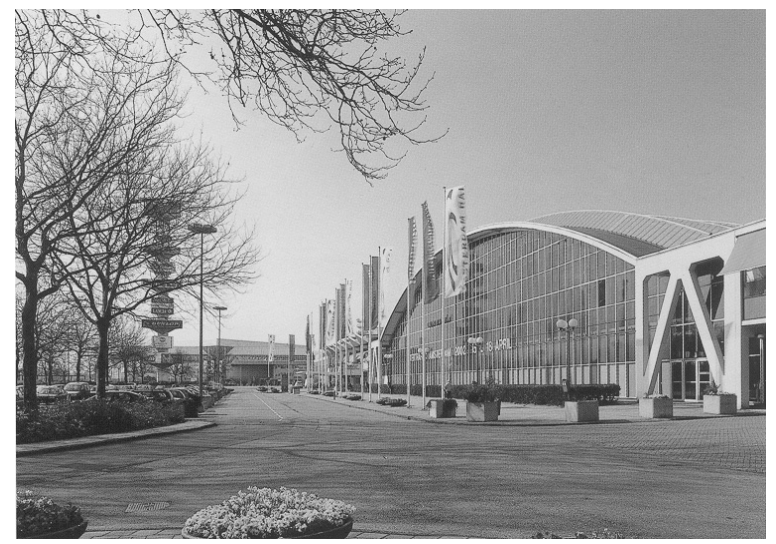

Figure 1: Europahal, RAI, Amsterdam, 1961. Triangular arched lattice trusses, with $67 \mathrm{~m}$ span. Concrete cross beams take up the lateral thrust force.

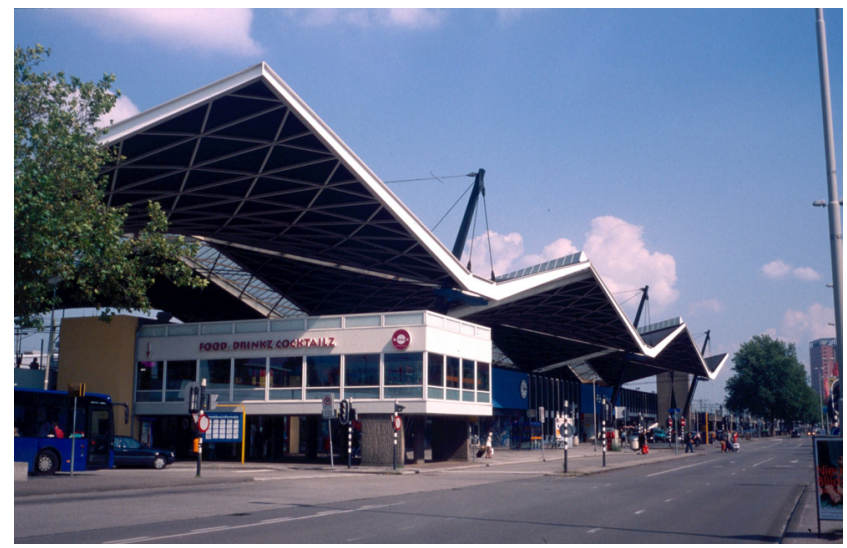

Figure 2: Tilburg Railway Station, 1965. Hypar shells with steel frames suspended from steel masts and supported by concrete columns. 
For manufacturing and storage halls often the usual lattice trusses and plate girders were used. A large span can be found in the Europahal (1961) of the RAI complex in Amsterdam. Arched trusses, which were triangular in cross section, span $67 \mathrm{~m}$. The gently curving arch spans are supported on each side by concrete cross beams, which, to take up the truss forces, are linked to tie rods under the floor. One side of the each triangular truss and the end facades are glazed. The architecture also plays a role in the design of railway station roofs. An interesting example is the roof at Tilburg (1965). On the outside the hypar shell roofs with steel frames of $21 \times 21 \mathrm{~m}$ are suspended on steel pin-head columns, while on the inside they rest on concrete columns.

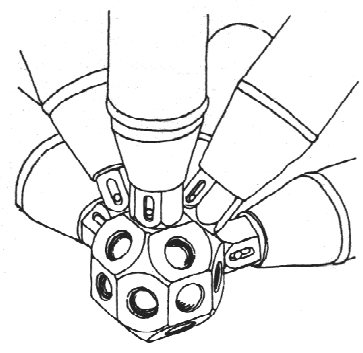

Figure 3: Mero-system. All the bars are tubular. They are bolted onto steel nodes.

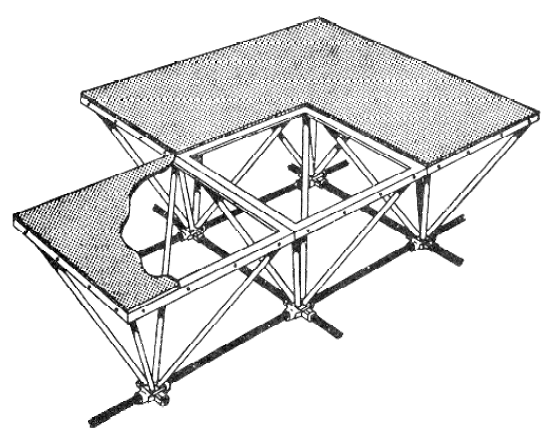

Figure 4: $\quad$ Space-deck system. The upper edges of the pyramids are angle profiles, the diagonal, tubes and the lower edges are solid round bars.

Rows of roof lights are installed between the shells.

The architecture also plays a role in the design of railway station roofs. An interesting example is the roof at Tilburg (1965). On the outside the hypar shell roofs with steel frames of $21 \times 21 \mathrm{~m}$ are suspended on steel pin-head columns, while on the inside they rest on concrete columns. Rows of roof lights are installed between the shells.

At the end of the sixties space frames were introduced. These are plate-like roof structures and are thus primarily suitable for square plans. Because the load 
is transferred to more edges or columns they can take up point loads very well. Early examples are the Martinihal in Groningen (1969), the Turfschip at Breda, and the Amstelhal of the RAI, Amsterdam. The spans are considerably bigger, being respectively $40 \mathrm{~m}, 29 \mathrm{~m}$ and $40 \mathrm{~m}$. In Groningen the Mero system and in Breda, the Space-deck system were used while the Amstelhal is unbranded. In the Mero-system all the elements are tubular. The tubes are bolted onto cast iron junction nodes. The Space-deck system is built up from pyramids that point downwards.

The upper edges are angle profiles, the diagonals are tubular and the under edges massive round bars. After 1970 existing or new systems were used in the Netherlands. . The space frame could be entirely constructed at ground level and then lifted into position. It was also possible to build onto structures that had been lifted into position.

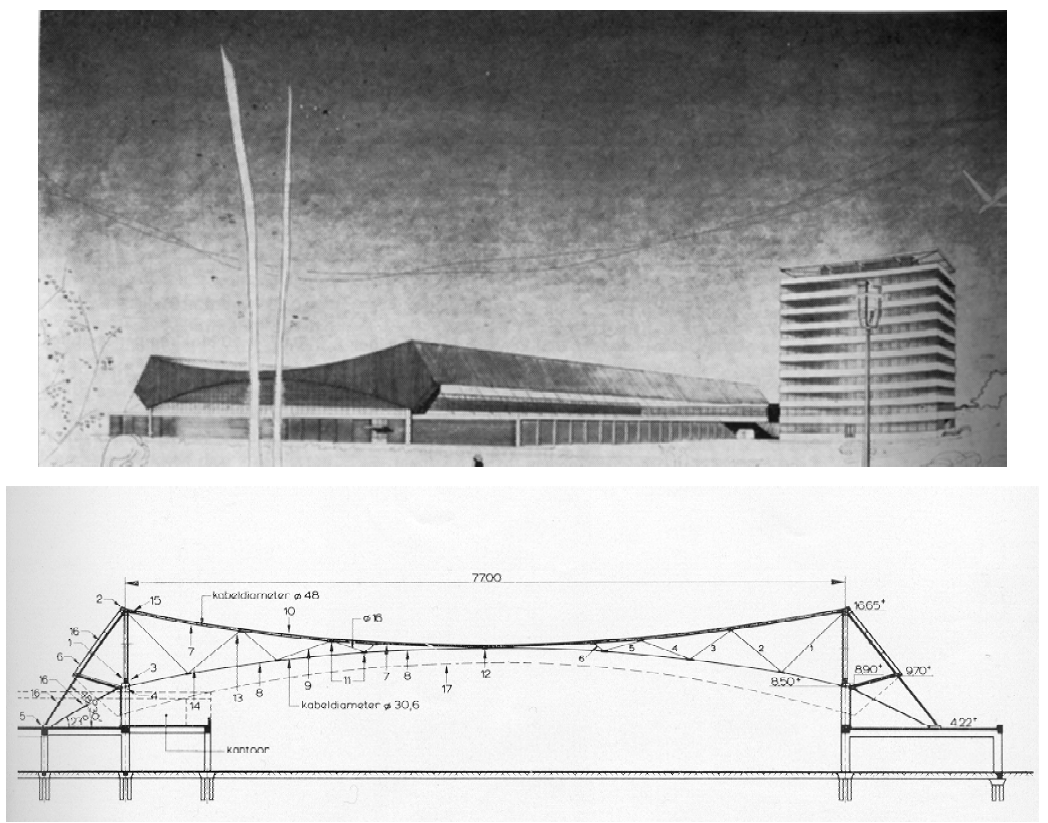

Figure 5: Air freight centre, Schiphol Airport, 1967. Spanned by Jawerth spans that are entirely constructed from cables.

It was noteworthy that the roofs were almost always made of profiled steel plates or wooden sheeting. In this case the roof had a clear span direction. Only the Martinihal were square sandwich elements that do justice to the principle of space frames used.

The Jawerth cable truss is a light roof structure that is primarily suited for large spans. It consists of a gently curving upper cable and a similar lower cable that are connected by diagonal cables. An early use of this system was for the ice stadium in Stockholm (1962). In addition to their being light and inexpensive, these systems require only a relatively short construction time. 
Jawerth trusses were used for the sport and music hall in Kerkrade (1966), and the airfreight centre at Schiphol (1967). The spans were 61 and $78 \mathrm{~m}$ respectively.

With vertical downward tension the tension in the upper cable increases, while that in the lower cable decreases. With upward wind loads the forces are opposite.

The cable is held under tension by a weight, or possibly anchored in the ground. Horizontal purlins run over the cables and these support the roof panels. Because the stiffness of the beams is low the skin of the roof must be somewhat flexible. Shell structures are mainly used for halls and less often for multi-storey buildings, however there are a few such buildings, including the Municipal Administrative Office of Amsterdam (1960) and the Aeronautical (1965) and Electro-Technical (1969) Departments of Delft University of Technology. The ments with concrete cladding or a concrete skeleton reinforced with steel profiles.

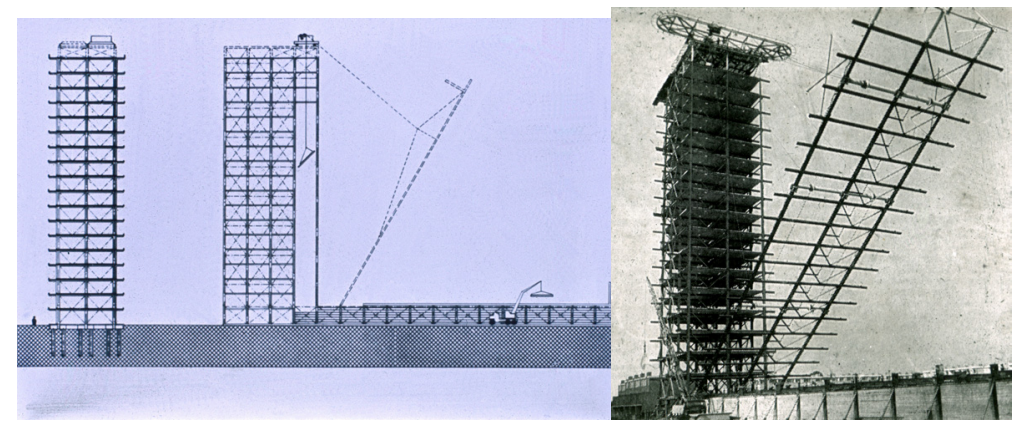

Figure 6: Porte-de-Lilas system. Frames are constructed horizontally and then raised, after which the floors are laid.

Floor slabs are usually thin. Even in 1964 the use of steel beams and concrete floor slabs was a recognised construction method. Stability was provided by walls and cores of reinforced concrete or by bending stiff steel frames.

The Port-de-Lilas system is a construction system for multi-storey buildings that is named after the part of Paris where it was first used. A one- span wide tower was built in the traditional manner. On this a winch system was installed. The frame for the next span was assembled on the ground and hoisted up until it was vertical. It was then connected to the first structure by spacers. Next the floor slabs, which were also prefabricated on the ground, were hoisted up. The winch installation was then moved one span further.

The truss for the following span was then assembled on the ground and raised into position (after which the winch moved one span further). In this way a hotel was built in Amsterdam and an apartment building and student flats were built in Delft in very short building times. The layout of the apartments was very flexible, since there were no bearing walls separating the dwellings (and the walls were not bearing walls). 


\section{Concrete structures}

\subsection{Material}

In the above sections, mention has already been made of the favourable position of concrete compared to steel. The quality and strength of both cement mixtures and reinforcement steel improved. This became especially advantageous when cement mixing started to take place in the American way in a factory instead of on site. The composition of the mixture no longer depended on volume, but on the weight of the components and on screening curves. The quality of the cement improved to American standards. Initially the dry components were mixed on a lorry and water was added shortly before the casting process; at the end of the 1940s agitator systems were added. The ready made mixture was then transported to the building site in a mixer. The distance travelled could not exceed $15 \mathrm{~km}$. In the Netherlands much work was carried out by the Betonvereeniging (Cement Association). They promoted the use of this material and the dissemination of knowledge in the form of books and the journal 'Cement' which was first issued in 1949. The Association provided courses and established many committees for such matters as research projects, prefabrication and the development of prestressed concrete.
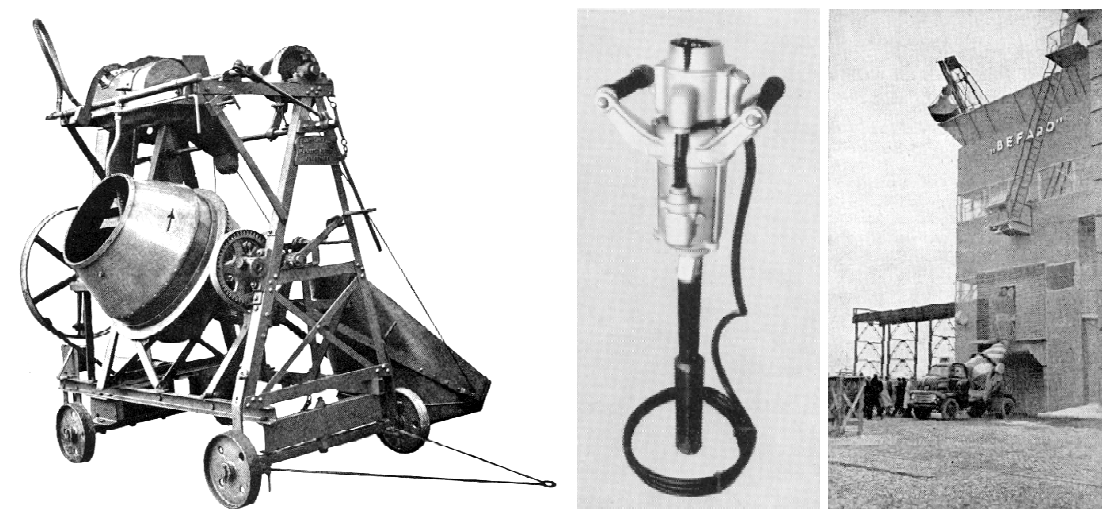

Figure 7: Electric concrete mixer, compacter and the first concrete mortar factory, Belfaro, Rotterdam.

Something has already been said about the methods of calculating steel. With regard to concrete there was a move from elastic calculation to the elasto-plastic method. Braces were also more often used to take up transverse forces rather than bent reinforcement bars.

The amount of construction equipment on site also increased. Cranes were bigger and monorail transport installations were also introduced, as well as concrete pumps and better equipment for consolidation.

Prestressed concrete was developed, so slimmer structures could be constructed. This presented the architect with new opportunities and more 
buildings with open space on the ground floor and cantilevered extensions appeared.

In France prestressed concrete had already been used before 1940 and Eugène Freyssinet had contributed much to its development. A distinction must be made between prestressed concrete in which the tendons are stretched after the concrete has hardened (post-tensioned) and concrete where the tendons are stressed before the concrete has hardened (pre-tension). Pretensioned beams were made in factories. Hardening was accelerated by steaming the fresh concrete.

\subsection{Building methods}

During this period there were labour shortages and the construction industry was very busy and prefabrication progressed rapidly. Usually the elements were made in a factory; a high quality could be attained and the moulds and formwork could be used many times. Prefabrication was strongly promulgated by Delft University of Technology and was subsidised by the government. A Dutch invention from 1934 was the shock-vibration process. The composition of the mixture was carefully controlled and only the amount of water required for the hardening was added. The contents of the filled mould were vibrated on a 'shock table'.

Numerous systems were developed for residential buildings from the smallest to the biggest elements. A separate study of these systems was made, which, amongst other things investigated their adaptability. This publication considers only residential and utility buildings.

Prefabricated halls consist of columns, main trusses, girders, purlins and roof slabs, possibly provided with roof-light rows. When the size was limited by the material these elements are prefabricated in sections and assembled on site. Many concrete manufacturers use their own construction systems.

For multi-storey buildings with a prefabricated skeleton stability was provided by a core and walls cast in situ. In relation to the flexibility the floors sometimes had spans of $10 \mathrm{~m}$ to $15 \mathrm{~m}$. For these, single or double $\mathrm{T}$ slabs (possibly prestressed) were used. For an office building in Rotterdam (1967) the span was $12 \mathrm{~m}$ and the facade was constructed from $\mathrm{H}$-shaped elements.

For structures cast on site there were developments in the formwork materials and systems. In utility buildings universal formwork was used.

For structures cast on site there were developments in the formwork materials and systems. In utility buildings universal formwork was used. These were standard panels that were usually covered with plywood, but sometimes steel plates were used. To make waffle slab floors fibreglass moulds were placed on the formwork. The size of the elements was such that they could be placed manually, but they could also be used to construct large wall elements or tabular elements. Floor slab formwork was supported by scaffolding or struts, while climbing and sliding formwork was used to make the cores. The climbing formwork was one storey high. The formwork-adjusting mechanism and scaffolding formed a unit. The structures were attached to already hardened concrete by means of metal fixing points that were cast into the concrete. When 


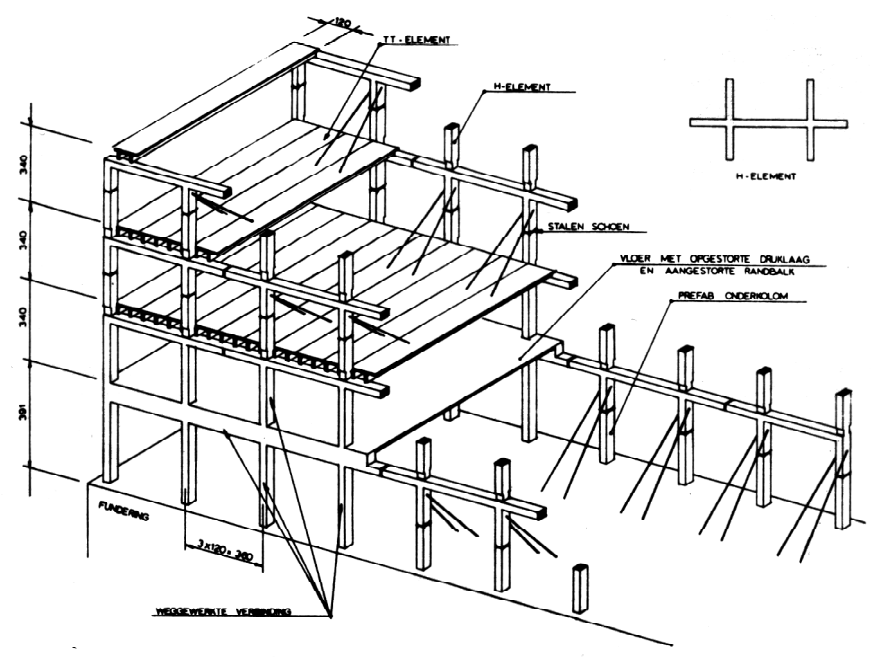

Figure 8: Albatross Superfosfaat office building, Rotterdam. Skeleton consisting of reinforced double $\mathrm{T}$ plates with $\mathrm{H}$ elements for the facades.
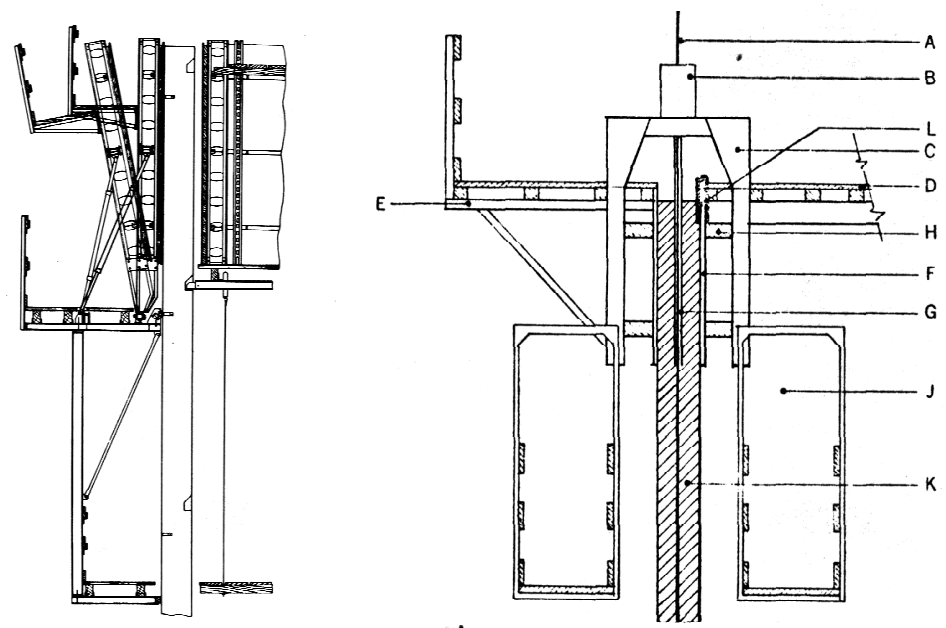

Figure 9: Formwork systems. Left a climbing formwork attached to a concrete wall that has already hardened. Right a sliding formwork that is raised pneumatically on climbing bars.

sliding formwork was being used to make the core the formwork was continuously drawn upward with the aid of jacks that pulled up trestles on vertical bars in the walls while the concrete was being poured.

Another system that is used in the Netherlands is the lift slab system. The floors are cast on top of each other, hydraulically lifted up to position and then anchored. For low buildings stability is provided by columns embedded in the 
foundations. For high buildings cores are used. Round the column there is a castin collar of profile steel. The lifting point is attached to this and the load is transferred by means of wedges on the column. All the facades and inside walls are light, which permits great flexibility. In this way a ten-storey office building was constructed at Schiphol. (1966).

Much internal transport can be avoided by using the jack-block system. With this system the top storey is made at ground level. It is then lifted up and the rough structure of the storey below is constructed. The construction of the top floor is then completed.

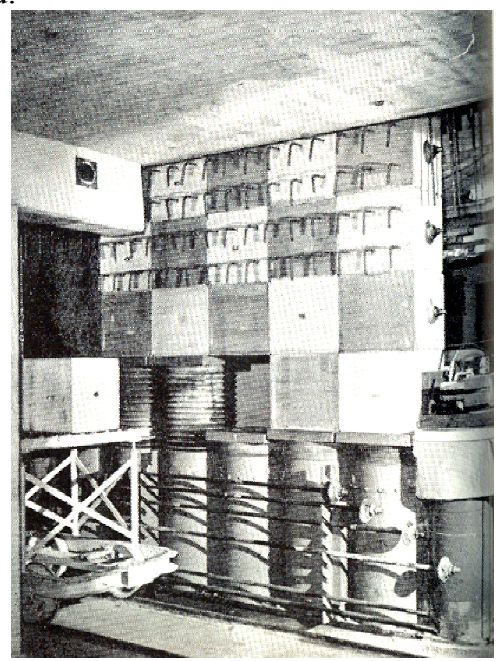

Figure 10: Jack-block system. The entire row of blocks is horizontally stressed. One jack is lowered and the next block is added. The hooks on the upper blocks are for the attachment of the floor.

Since 1965 a number of buildings for ministries in The Hague have been constructed in this way. The walls were lifted by hydraulic jacks. On these jacks were placed blocks that were horizontally stressed. After one jack had been released the following block was placed on it and the jack was again engaged. This action was repeated for the following jacks in sequence. The row of new blocks was then again attached. The remaining walls were cast later. When there were three or four blocks on top of each other these were replaced by a column element. In a later variation of the system the temporary blocks were replaced by panels. This was called the jack-panel system.

It is remarkable how many shell roofs were built during this period. They take the form of domes, barrels, sheds and hypar or folded shells. Around half of these were made of prestressed concrete. Most were monolithically cast, but there are also shells that are composed of prefabricated elements. They are usually $6-8 \mathrm{~cm}$ thick.

An early form of the use or prestressing can be found in the shed shells of the Jamin factory in Oosterhout (1955). The shells are $40 \mathrm{~m}$ long. The Freyssinet system was used to prestress both the shell and the edge beams. The structural 
design was made by Prof. Dr. Ir. A.M. Haas, Professor of Concrete structures, Delft University of Technology. Model tests were carried out in order to investigate the distribution of forces. The dome of the ANWB (Automobile Association) building in The Hague (1961) and the Christoffel Church in Coberg (1961) are early examples of the use of prestressed prefabricated elements. The Fusée Céramique is an unusual construction method. Small terracotta tubes are laid in the mortar on a curved formwork, after which the concrete is poured into the formwork. Many roofs of halls have been constructed in this way, especially in the south of the Netherlands.

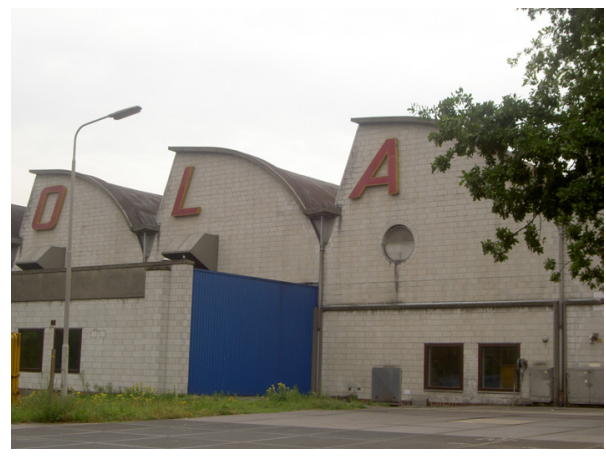

Figure 11: Jamin Factory, Oosterhout, 1955. Steel shells with a $40 \mathrm{~m}$ span.

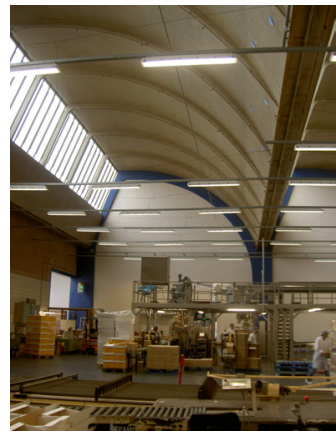

Figure 12: The Freyssinet system was used to prestress both the shells and edge beams.

\section{Conclusion}

The reconstruction period was a time of renewal. First materials were scarce and it was necessary to be economical with them. At the end of the fifties labour costs rose and at the same time it was necessary to reduce the construction time. This led to many innovative new construction systems, which were often very repetitive, so that the buildings of that period are often considered to be very monotonous. From the point of view of transformation it is obvious that often very large floor areas can be created. This paper is only a brief outline and sketch and further research is recommended. This should provide a better view of the historical-cultural value and the possibilities for transformation.

\section{References}

[1] Dijk, H. Van, Hogeslag, H., Schultz, E., Vooronderzoek, Ontwikkelingen in het construeren van gebouwen gedurende de wederopbouwperiode, Zoetermeer, 2004 